This article was downloaded by: [National Sport Info Centre]

On: 6 October 2008

Access details: Access Details: [subscription number 788740410]

Publisher Taylor \& Francis

Informa Ltd Registered in England and Wales Registered Number: 1072954 Registered office: Mortimer House, 37-41 Mortimer Street, London W1T 3JH, UK

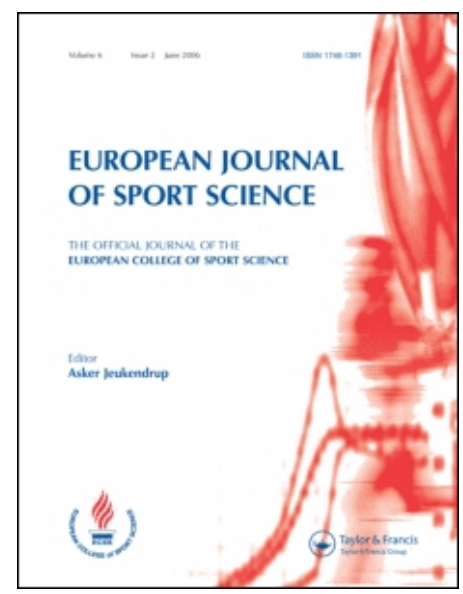

European Journal of Sport Science

Publication details, including instructions for authors and subscription information:

http://www.informaworld.com/smpp/title content=t714592354

\title{
Muscle damage, inflammation, and recovery interventions during a 3-day basketball tournament
}

Paul G. Montgomery a; David B. Pyne a; Amanda J. Cox a; Will G. Hopkins b; Clare L. Minahan c; Patrick H. Hunt ${ }^{\mathrm{d}}$

a Department of Physiology, Australian Institute of Sport, Belconnen, Australia ${ }^{b}$ Department of Sport and Recreation, Auckland University of Technology, Auckland, New Zealand ${ }^{\circ}$ Physiotherapy and Exercise Science, Griffith University, Gold Coast, Australia ${ }^{\mathrm{d}}$ Basketball Australia, Sydney, Australia

Online Publication Date: 01 September 2008

To cite this Article Montgomery, Paul G., Pyne, David B., Cox, Amanda J., Hopkins, Will G., Minahan, Clare L. and Hunt, Patrick H.(2008)'Muscle damage, inflammation, and recovery interventions during a 3-day basketball tournament',European Journal of Sport Science, $8: 5,241-250$

To link to this Article: DOI: $10.1080 / 17461390802251844$

URL: http://dx.doi.org/10.1080/17461390802251844

PLEASE SCROLL DOWN FOR ARTICLE

Full terms and conditions of use: http://www.informaworld.com/terms-and-conditions-of-access.pdf

This article may be used for research, teaching and private study purposes. Any substantial or systematic reproduction, re-distribution, re-selling, loan or sub-licensing, systematic supply or distribution in any form to anyone is expressly forbidden.

The publisher does not give any warranty express or implied or make any representation that the contents will be complete or accurate or up to date. The accuracy of any instructions, formulae and drug doses should be independently verified with primary sources. The publisher shall not be liable for any loss, actions, claims, proceedings, demand or costs or damages whatsoever or howsoever caused arising directly or indirectly in connection with or arising out of the use of this material. 


\title{
Muscle damage, inflammation, and recovery interventions during a 3-day basketball tournament
}

\author{
PAUL G. MONTGOMERY ${ }^{1}$, DAVID B. PYNE ${ }^{1}$, AMANDA J. COX ${ }^{1}$, WILL G. HOPKINS ${ }^{2}$, \\ CLARE L. MINAHAN ${ }^{3}$, \& PATRICK H. HUNT ${ }^{4}$ \\ ${ }^{1}$ Department of Physiology, Australian Institute of Sport, Belconnen, Australia, ${ }^{2}$ Department of Sport and Recreation, \\ Auckland University of Technology, Auckland, New Zealand, ${ }^{3}$ Physiotherapy and Exercise Science, Griffith University, Gold \\ Coast, Australia, and ${ }^{4}$ Basketball Australia, Sydney, Australia
}

(Received 06 March 2008; revised 28 April 2008; accepted 13 May 2008)

\begin{abstract}
Cold water immersion and compression garments are now popular strategies for post-exercise recovery. However, little information exists on the effectiveness of these strategies to minimize muscle damage, or any impact they may have on biomarker clearance after team sport competition. The main aim of this study was to investigate the time course of muscle damage markers and inflammatory cytokines during basketball tournament play. We also wished to examine if cold water immersion and compression recovery strategies ameliorate any post-game increases of these biomarkers, compared with traditional refuelling and stretching routines.

Male basketball players (age 19.1 years, $s=2.1$; height $1.91 \mathrm{~m}, s=0.09$; body mass $87.9 \mathrm{~kg}, s=15.1$ ) were asked to compete in a three-day tournament playing one game each day. Players were assigned to one of three recovery treatments: carbohydrate + stretching (control, $n=9$ ), cold-water immersion at $11^{\circ} \mathrm{C}$ for $5 \times 1 \mathrm{~min}(n=10)$; or full-leg compression at $18 \mathrm{mmHg}$ for $\sim 18 \mathrm{~h}(n=10)$. Players received their treatment after each game on three consecutive days. Venous blood samples were assayed before the tournament and at $10 \mathrm{~min}, 6 \mathrm{~h}$, and $24 \mathrm{~h}$ after each game for concentrations of the muscle damage markers fatty-acid binding protein (FABP), creatine kinase, and myoglobin; interleukin-6 (IL-6) and interleukin-10 (IL-10) were also assayed. Inferences were based on log-transformed concentrations.

Post-game increases in damage markers were clear and very large for FABP after the cold water immersion $(3.81 \times / \div$ 1.19 , factor mean $\times / \div$ factor $s$ ), compression $(3.93 \times / \div 1.46)$, and control $(4.04 \times / \div 1.19)$ treatments. Increases in myoglobin were also clear and very large after the cold water immersion $(3.50 \times / \div 1.35)$, compression $(3.66 \times / \div 1.48)$, and control $(4.09 \times / \div 1.18)$ treatments. Increases in creatine kinase were clear but small after the cold water immersion $(1.30 \times / \div 1.03)$, compression $(1.25 \times / \div 1.39)$, and control $(1.42 \times / \div 1.15)$ treatments, with small or unclear differences between treatments. There were clear moderate to large post-game increases in IL- 6 for cold water immersion $(2.75 \times / \div 1.37)$, compression (3.43 $\times / \div 1.52)$, and control (3.47 $\times / \div 1.49)$. Increases in IL-10 were clear and moderate for cold water immersion $(1.75 \times / \div 1.43)$, but clear and large after the compression $(2.46 \times / \div 1.79)$ and control $(2.32 \times / \div 1.41)$ treatments. Small decreases in IL-6 and IL-10 were observed with cold water immersion compared with the compression and control treatments, with unclear effects between treatments over the tournament. There was no clear benefit from any recovery treatment post-game, as the differences between treatments for all biomarker measures were small or unclear. Pre- to post-tournament increases in FABP, myoglobin, and creatine kinase were clearly small to moderate. There were also small to moderate differences between cold water immersion and the compression $(0.85$ $\times / \div 1.21)$ and control $(0.76 \times / \div 1.26)$ treatments for the post-tournament measures compared with pre-tournament. Pre- to post-tournament changes for IL- 6 and IL-10 were unclear, as were the differences between treatments for both cytokines.

Tournament basketball play elicits modest elevations of muscle damage markers, suggesting disruption of myocyte membranes in well-trained players. The magnitude of increase in muscle damage markers and inflammatory cytokines postgame ranged from small for creatine kinase, to large for IL-6 and IL-10, to very large for FABP and myoglobin. Cold water immersion had a small to moderate effect in decreasing FABP and myoglobin concentrations after a basketball tournament compared with the compression and control treatments.
\end{abstract}

Keywords: Intermittent exercise, recovery, team sport

Correspondence: P. G. Montgomery, Department of Physiology, Australian Institute of Sport, PO Box 176, Belconnen, ACT 2616, Australia. E-mail: paulm@saints.com.au 


\section{Introduction}

Basketball is a team sport characterized by many high-intensity repeated efforts (Janeira \& Maia, 1998) followed by rapid decelerations and eccentric loads in limited space. These demands are compounded by numerous jumps and changes in direction during both offensive and defensive movements (Abdelkrim, El Fazaa, \& El Ati, 2007; Janeira \& Maia, 1998; McInnes, Carlson, Jones, \& McKenna, 1995), and are likely to be amplified when games are played on consecutive days during tournaments. Compared with other muscle damage studies, basketball would be considered low-volume eccentric exercise. Adaptation to eccentric exercise can occur without significant muscle damage and associated symptoms (Mair et al., 1995; Nosaka, Sakamoto, Newton, \& Sacco, 2001). In addition, exposure to a small number of non-damaging eccentric contractions appears to provide protection and improve recovery from a subsequent damaging bout (Paddon-Jones \& Abernethy, 2001). This sequence of events implies that well-trained players may exhibit blunted responses to various serum muscle damage markers after play (Vincent \& Vincent, 1997).

Recovery practices, in particular cold-water immersion and the use of compression garments, are now an integral component of post-game activities in high-performance team sports. Little information exists on the effectiveness of these recovery strategies, in particular the extent to which they minimize muscle damage or enhance the clearance of waste products. Much of the literature regarding recovery strategies and muscle damage has employed aggressive eccentric loading protocols to induce large amounts of damage (Vaile, Gill, \& Blazevich, 2007). However, in team sports the amount of exercise-related damage may be considerably less than that evoked by controlled eccentric-biased exercise. Recently, a protocol using $3 \times 1$-min cold water immersion at $5^{\circ} \mathrm{C}$ had no impact on the clearance of creatine kinase (Sellwood, Brukner, Williams, Nicol, \& Hinman, 2007), a marker of muscle damage. Similarly, the use of constant cold water immersion at $10^{\circ} \mathrm{C}$ for $10 \mathrm{~min}$ following an intermittent exercise protocol had no impact on creatine kinase, but reduced serum myoglobin (Bailey et al., 2007), another marker of muscle damage. In contrast, the use of contrast water therapy and compression independently both enhanced the removal of creatine kinase compared with a control treatment after a single rugby match (Gill, Beaven, \& Cook, 2006) and a repeat sprint trial (Duffield \& Portus, 2007). Further research is needed to clarify these conflicting reports.

Muscle damage essentially occurs in two phases. First, mechanical damage to the contractile unit or plasma membrane occurs primarily due to the eccentric component of muscle movement. This insult may initiate metabolic/chemical pathways in the following hours or days, creating further damage due to factors such as calcium influx, decreased membrane resistance, and free-radical production. These events lead to a generalized inflammatory cascade in response to muscle damage, which involves the release of various cytokines responsible for the initiation and moderation of the inflammatory response. Although serum creatine kinase has been used extensively in studies to assess the extent of muscle damage, measurements should be interpreted carefully, as the response to an initial exercise bout can remain elevated for several days. Fatty-acid binding protein (FABP) and myoglobin are found in relatively large amounts in skeletal muscle. Measurement of FABP and myoglobin may overcome the shortcomings of interpreting post-exercise changes in creatine kinase concentrations and muscle damage, as values typically peak $30 \mathrm{~min}$ after exercise and return to baseline $\sim 24 \mathrm{~h}$ after exercise (Sorichter et al., 1998; Sorichter, Puschendorf, \& Mair, 1999), allowing observations of acute changes.

Cytokines play an important role in the inflammatory response to muscle damage and subsequent repair process. Interleukin 6 (IL-6) increases after exercise as a function of exercise intensity and duration (Febbraio \& Pedersen, 2002; Pedersen \& Febbraio, 2005; Pedersen et al., 2003). The suggested roles of IL-6 during and after exercise include regulation of carbohydrate utilization, stimulation of the restoration of damaged or depleted muscle proteins, mobilization and activation of neutrophils, and suppression of further muscle damage (Shephard, 2002). Interleukin 10 (IL-10) plays an important role in containing and resolving the inflammatory process via suppression of pro-inflammatory cytokines (Peterson \& Pedersen, 2005). To date, there is no evidence detailing the concentration of these cytokines following a single basketball game or a series of games over several days or their relationships with traditional markers of muscle damage. The aims of the present study were to examine changes in blood markers of muscle damage and inflammation associated with a multi-game basketball tournament, and to determine whether recovery practices have a substantial effect in ameliorating increases in the circulating concentrations of these biomarkers.

\section{Methods}

\section{Participants}

Twenty-nine male basketball players (age 19.1 years, $s=2.1$; height $1.91 \mathrm{~m}, s=0.09$; body mass $87.9 \mathrm{~kg}$, 
$s=15.1$; sum of 7 skinfolds $68.9 \mathrm{~mm}, s=32.1$ ), competing regularly in State competitions, participated in the study. Players had several weeks of specific pre-season training before the study tournament. Players were provided with written and verbal information on the objectives of the study, and completed an informed consent document before participation. The study was approved by the associated institutions' Human Research Ethics Committees.

\section{Experimental design}

The study involved a randomized controlled experimental design of parallel groups, investigating the impact of successive days of basketball play on the muscle damage markers of creatine kinase, myoglobin, and FABP, together with the cytokines IL- 6 and IL-10. We also wished to determine whether the application of common recovery practices had a substantial impact on the concentrations and clearance rates of these biomarkers after a single game, and over the pre- to post-tournament period. All participants were asked to volunteer for, and participate in, a three-day mini-tournament involving one full 48-min game per day. Players and groups were matched for positional and physical characteristics and assigned to one of three treatment groups: carbohydrate + stretching (control, $n=9$ ), cold water immersion $(n=10)$, and compression garments $(n=$ 10). This allocation ensured that the treatment groups had equal numbers of participating players with similar characteristics, and that players received similar game time. Immediately after each game, all players completed the control condition of carbohydrate replenishment plus stretching, regardless of supplementary treatments.

\section{Carbohydrate + stretching}

All players were directed through a standardized post-game recovery programme of 10 stretches completed twice bilaterally for $15 \mathrm{~s}$ to the legs and lower back ( $\sim 10 \mathrm{~min}$ in duration), and consumed a post-game carbohydrate snack $\left(1 \mathrm{~g} \mathrm{~kg}^{-1}\right.$ of body mass, containing $600 \mathrm{ml}$ of fluid). These procedures were considered representative of the "typical" minimum post-game practice for basketball and constituted the control group for this study. The players in the control group did not participate in any further recovery protocols.

\section{Compression}

Immediately after the standard post-game recovery and after showering, participants in the compression group were asked to change into full-length lowerlimb compression garments (LineBreak ${ }^{\mathrm{TM}}$, Sydney, Australia; $\sim 18 \mathrm{mmHg}$ ) for the post-game and overnight period $(\sim 18 \mathrm{~h})$. Both the control and compression groups rested passively for $15 \mathrm{~min}$ while the participants in the cold water immersion group completed their treatment.

\section{Cold water immersion}

Following the standard post-game recovery, participants in the cold water immersion group immersed their entire body, to the mesosternale level, in a cold water plunge pool $\left(11^{\circ} \mathrm{C}\right)$ for $5 \times 1$-min intervals. Between immersions, players rested passively in ambient air $\left(\sim 23^{\circ} \mathrm{C}\right)$ for $2 \mathrm{~min}$.

\section{Daily measures}

At the same time each morning during the tournament $(\sim 08.00$ to $09.00 \mathrm{~h})$, all participants rested supine for $10 \mathrm{~min}$ before providing an $8-\mathrm{ml}$ blood sample (Figure 1). All samples were collected from a forearm vein using standard venepuncture techniques. Players then completed daily tests including mid-thigh girth measurements, body mass, and a visual analogue scale (VAS) for leg soreness, with descriptors ranging from 1 ("normal") to 10 ("extremely sore"). A general fatigue scale with descriptors ranging from 1 ("not at all") to 10 ("extremely
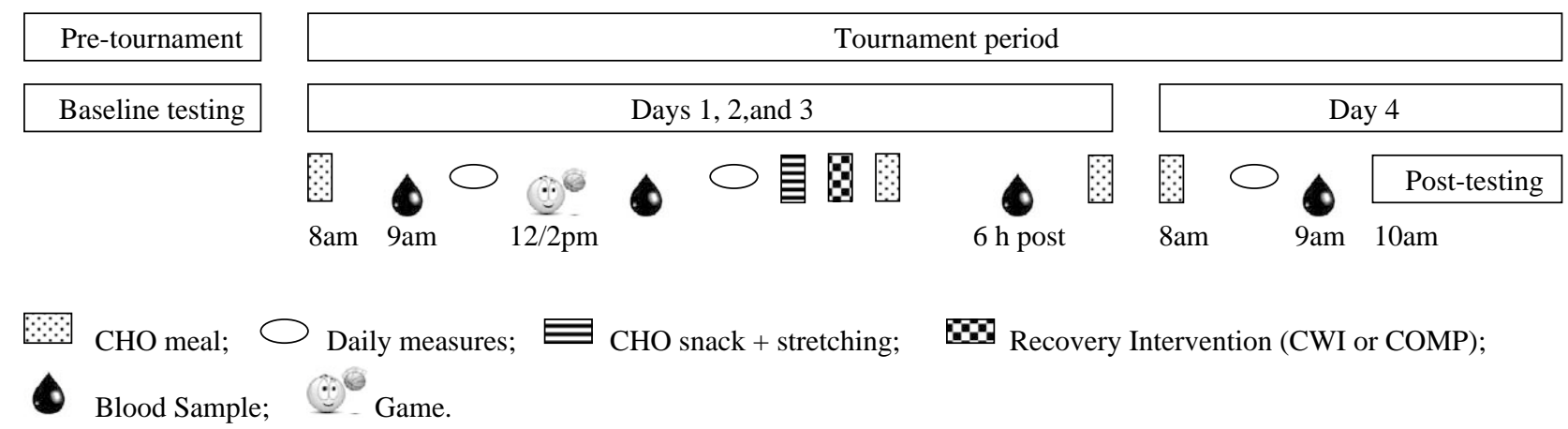

Recovery Intervention (CWI or COMP);

Figure 1. Schematic representation for the time-line of events during the tournament. 
tired") was also completed. Players then prepared for and completed their daily game (at either 12.00 or $14.00 \mathrm{~h}$ ) in accordance with the normal team arrangements. Coaches were asked to ensure similar game time for players across the three competitive games. After each game, all participants towelled dry, rested supine for $10 \mathrm{~min}$, and provided a second 8-ml blood sample. Participants were then reassessed for body mass, VAS, and mid-thigh and mid-calf girths before completing the standard postgame recovery programme of stretching and carbohydrate consumption. Participants in the cold water immersion and compression groups then performed their respective recovery treatment. A final $8-\mathrm{ml}$ blood sample was collected $6 \mathrm{~h}$ after the end of each game.

\section{Nutritional control}

Given the reported influence of dietary carbohydrate content on cytokine responses to exercise (Starkie, Arkinstall, Koukoulas, Hawley, \& Febbraio, 2001), dietary intake for all players was controlled to achieve a consistent daily carbohydrate intake of 8 $\mathrm{g} \cdot \mathrm{kg}^{-1}$ of body mass (Burke, 2001). The carbohydrate content of all foods and fluids was provided in the form of 30-g "blocks". Each player was instructed by a member of the research team to ensure the amount of carbohydrate for each meal was replicated on each day. A self-reported food diary was used to record all food and fluid consumed throughout the study period. Carbohydrate intake was analysed using FoodWorks Professional Edition, Version 3.01 (C) 1998-2005, Xyris Software, Australia). All players were allowed to drink water ad libitum, with carbohydrate sports drinks being excluded during play.

\section{Muscle damage and inflammatory markers}

All blood samples were collected directly into a serum separator collection tube (Greiner Bio-one; Frickenhausen, Germany). Serum was separated by centrifugation at $4000 \mathrm{rev} \cdot \mathrm{min}^{-1}$ for $5 \mathrm{~min}$ and stored frozen at $-80^{\circ} \mathrm{C}$ until analysis. Myoglobin and the cytokines IL- 6 and IL-10 were measured in serum using an Immulite 1000 solid phase chemiluminescent immunometric assay system (Diagnostics Products Corporation, CA, USA) and commercially available assay kits (Diagnostics Products Corporation, CA, USA). Creatine kinase concentrations were determined using a Hitachi 911 automated clinical chemistry analyser (Roche Diagnostics Corporation, Indianapolis, IN, USA) and commercially available reagents (Roche Diagnostics Corporation). Coefficients for the analyses of myoglobin, IL-6, and IL-10 were $0.9 \%, 2.2 \%$, and $1.4 \%$ respectively.
Concentrations of FABP were determined using a commercially available (Hycult Biotechnology, Uden, Netherlands) two-site enzyme immunoassay kit as described previously (Wodzig, Pelsers, Van der Vusse, Roos, \& Glatz, 1997). A standard curve of HFABP concentrations versus absorbance values was constructed using Workout Software Version 2.0 (Dazdaq Ltd., East Sussex, UK). H-FABP concentrations for samples were determined by extrapolation from this standard curve. Results for each ELISA were accepted if the correlation coefficient for the standard curve was greater than 0.99 and the high and low controls were within established ranges. The percent coefficient of variation for duplicate samples was $11.7 \%$.

\section{Statistical analysis}

Mean effects of the recovery treatments on muscle damage and inflammatory markers were estimated using the mixed model (Proc Mixed) in the Statistical Analysis System (Version 8.2, SAS Institute, Cary, NC, USA). Given that the players were on the court for different lengths of time, the mean cumulative game time was used as a covariate. Effects were expressed as factor changes by analysing log-transformed values. Precision of estimates were indicated with $90 \%$ factor confidence limits. Magnitude-based inferences of the effect of the recovery treatments were made by standardizing changes using betweenparticipant pre-tournament standard deviations. Qualitative magnitudes of standardized effects were assessed using the following scale: trivial $<0.2$, small $0.2-0.6$, moderate $0.6-1.2$, large $1.2-2.0$, and very large $>2.0$ (Hopkins, 2006).

\section{Results}

Pre- to post-game changes

Pre- to post-game increases were clear and very large for FABP after cold water immersion $(3.81 \times 1 \div$ 1.19 , factor mean $\times / \div$ factor $\cdot s)$, compression $(3.93 \times / \div 1.46)$, and the control treatment (4.04 $\times / \div 1.19$ ) (Figure 2a). Increases in myoglobin were also clear and very large after cold water immersion $(3.50 \times / \div 1.35)$, compression $(3.66 \times / \div 1.48)$, and the control treatment $(4.09 \times / \div 1.18)$ (Figure $2 b$ ). Increases in creatine kinase were clear but small after cold water immersion $(1.30 \times / \div 1.03)$, compression $(1.25 \times / \div 1.39)$, and the control treatment $(1.42 \times /$ $\div 1.15$ ) (Figure 2c). There was no clear benefit from any recovery treatment, as the differences between treatments for all muscle damage markers at postgame measures were small or unclear.

There were clear moderate post-game increases in IL-6 for cold water immersion $(2.75 \times / \div 1.37)$, 
a - - - Control

$\rightarrow$ - Cold-warer immersion
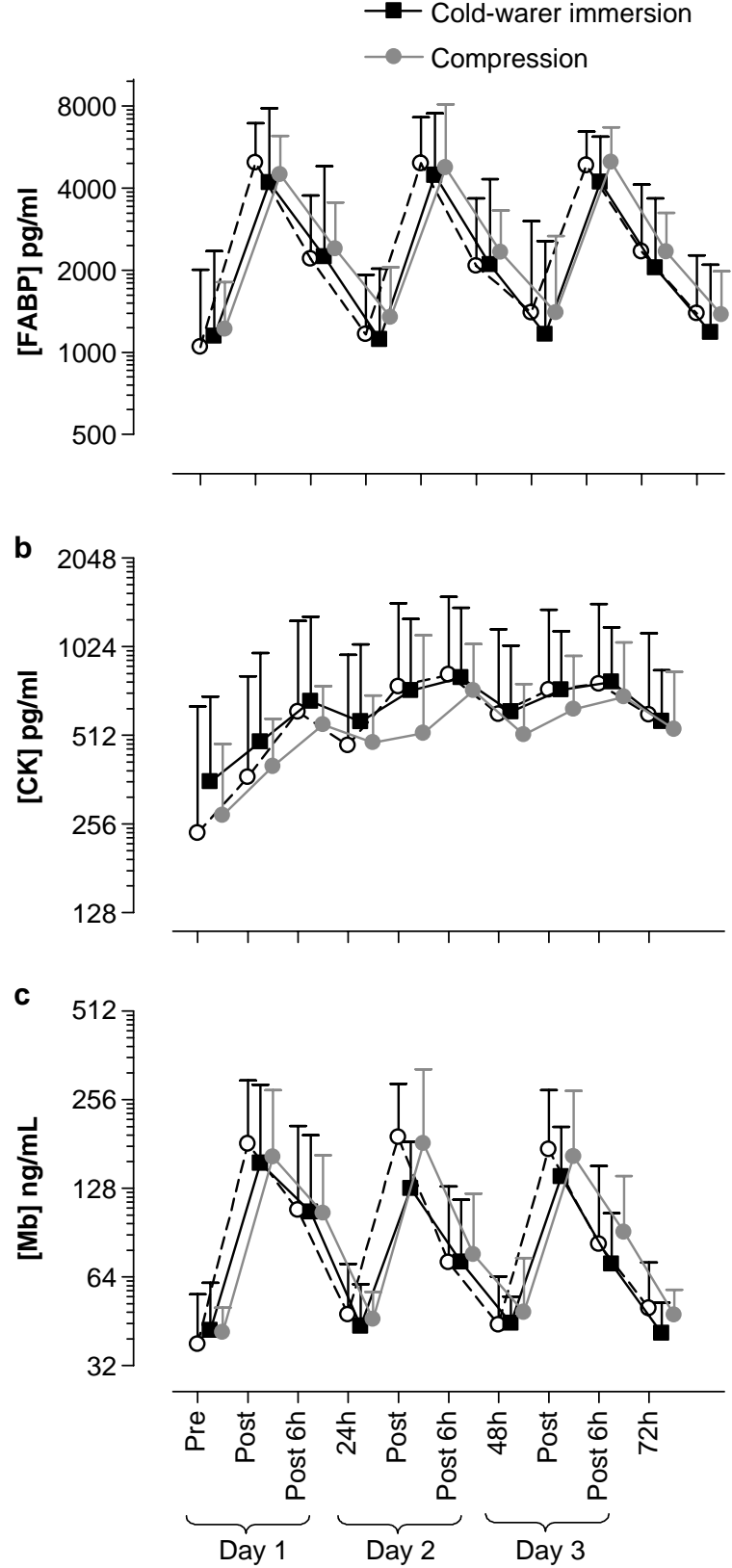

Figure 2. Concentrations of muscle damage markers and cytokines during a three-game basketball tournament. Values are logtransformed means and standard deviations. Moderate to very large increases were observed in the immediate post-game measure for FABP, myoglobin $(\mathrm{Mb})$, and cytokines. Compared with compression and the control condition, cold water immersion had a moderate beneficial impact on reducing biomarker concentration the morning following a game. Creatine kinase (CK) did not return to baseline before the next game, and these concentrations appeared to plateau over the third day.

compression $(3.43 \times / \div 1.52)$, and the control treatment $(3.47 \times / \div 1.49)$. Increases in IL-10 were clear and moderate for cold water immersion $(1.75 \times / \div$ 1.43), but clear and large for compression $(2.46 \times /$ $\div 1.79)$ and the control treatment $(2.32 \times / \div 1.41)$
(Figure 3). There was no clear benefit from any recovery treatment, as the differences between treatments for IL- 6 and IL-10 at post-game measures were small or unclear.

\section{Changes $6 h$ after the game and recovery}

Compared with post-game measures, serum concentrations of FABP $6 \mathrm{~h}$ after recovery showed clear moderate to large decreases after cold water immersion $(0.47 \times / \div 1.12)$, compression $(0.51 \times / \div 1.16)$, and the control treatment $(0.43 \times / \div 1.34)$. Myoglobin showed clear large to very large decreases after cold water immersion $(0.56 \times / \div 1.11)$, compression $(0.53 \times / \div 1.23)$, and the control treatment $(0.47 \times /$ $\div 1.17)$. Creatine kinase continued to have clear but small increases after cold water immersion $(1.18 \times /$ $\div 1.04)$, compression $(1.25 \times / \div 1.21)$, and the control treatment $(1.26 \times / \div 1.06)$.
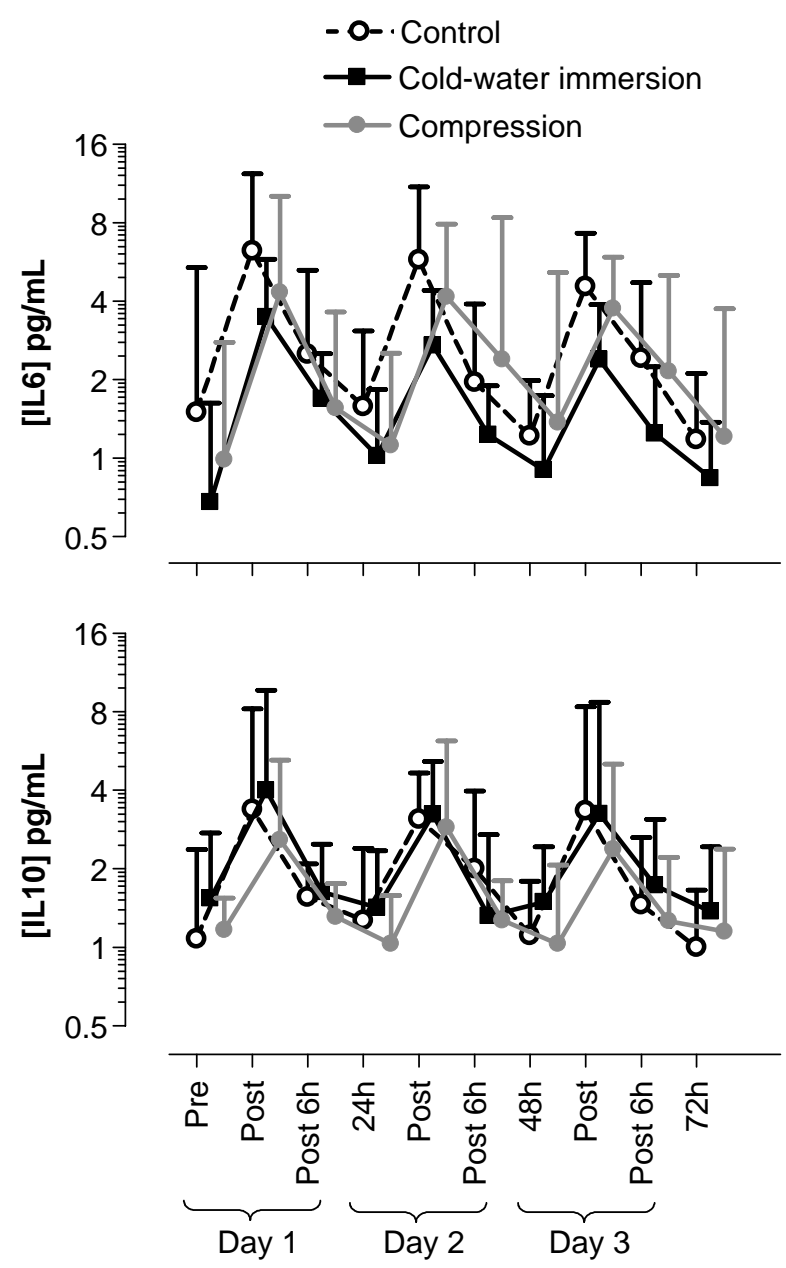

Figure 3. Concentrations of cytokines IL-6 and IL-10 during a three-game basketball tournament. Values are log-transformed means; error bars are standard deviations. Post-game IL-6 saw small decreases after cold water immersion over the tournament compared with compression and the control treatment. 
Interleukin-6 showed clear moderate decreases after cold water immersion $(0.51 \times / \div 1.35)$, clear small decreases after compression $(0.57 \times / \div 1.28)$, and clear moderate decreases after the control treatment $(0.46 \times / \div 1.53)$. Similarly, IL-10 had clear moderate decreases after cold water immersion $(0.55 \times / \div 1.64)$ and the control treatment $(0.62 \times /$ $\div 1.20$ ), but clear large decreases after compression $(0.47 \times / \div 1.23)$. There was no clear benefit of any recovery intervention being more useful in reducing cytokine concentrations $6 \mathrm{~h}$ after recovery, as the differences between treatments were small and unclear (Figure 3). Similarly, there was no clear impact on cytokine concentrations, with only small and unclear differences between treatments (Figure 3).

\section{Pre- to post-tournament changes}

The cumulative effect of 3 days of competition play and the impact of recovery interventions on serum biomarkers are shown in Table I. Cold water immersion recovery had the greatest impact on muscle damage marker concentrations, with lower post-tournament elevations in FABP and myoglobin, but not creatine kinase, which had a moderate increase (Figure 2). For comparisons between recovery treatments, the decrease in damage marker concentrations were small to moderate for cold water immersion compared with the control treatment. Compression appears to have had minimal benefit, as the comparisons with the control treatment were generally unclear after the competition period (Figure 2).

Changes to cytokine concentrations were unclear after 3 days of competition. Additionally, there was no clear impact from any recovery intervention, with no difference between treatments for both IL-6 and IL-10 (Figure 3).

\section{Muscle soreness}

Pre- to post-tournament leg muscle soreness (1-10 scale) increased substantially in all groups (Figure 4a). Players rated leg soreness after the first game as "uncomfortable" (3 units), which increased to "sore" (5 units) after the third game (Figure 4a). The immediate mean post-game muscle soreness rating was "somewhat sore" (4.2 units, $s=1.4)$, which decreased to "normal" (2.0 units, $s=0.7)$ after the cold water immersion protocol. The perception of soreness rebounded back to "uncomfortable" (3.1 units, $s=1.2$ ) on the next morning. Cold water immersion was substantially better in minimizing soreness with large and very large decreases compared with compression and the control treatment. There were also large increases in

Table I. The effect of different recovery treatments on the pre- to post-tournament changes in muscle damage markers and inflammatory cytokine concentrations (factor mean $\times 1 \div$ factor $\mathrm{s}$ ), with the associated effect size and qualitative outcome shown in italics

\begin{tabular}{|c|c|c|c|c|c|c|}
\hline & \multicolumn{3}{|c|}{$\begin{array}{c}\text { Changes } \\
\text { (factor mean } \times / \div \text { factor } s \text { ) } \\
\text { Effect size; } \pm C L \\
\text { Qualitative outcome }\end{array}$} & \multicolumn{3}{|c|}{$\begin{array}{c}\text { Effects } \\
\text { (factor mean } \times 1 \div 90 \% \text { factor CL) } \\
\text { Effect size } ; \pm C L \\
\text { Qualitative outcome }\end{array}$} \\
\hline & CWI & COMP & $\mathrm{CON}$ & $\mathrm{COMP} / \mathrm{CON}$ & $\mathrm{CWI} / \mathrm{CON}$ & CWI/COMP \\
\hline $\begin{array}{l}\text { Fatty-acid binding } \\
\text { protein }\end{array}$ & $\begin{array}{l}0.98 \times / \div 1.15 \\
-0.03 ; \pm 0.24 \\
\quad \text { Unclear }\end{array}$ & $\begin{array}{l}1.16 \times / \div 1.17 \\
0.25 ; \pm 0.26, \\
\text { Small } \uparrow\end{array}$ & $\begin{array}{l}1.30 \times 1 \div 1.23 \\
0.44 ; \pm 0.35 \\
\quad \text { Small } \uparrow\end{array}$ & $\begin{array}{l}0.89 ; \times / \div 1.27 \\
-0.19 ; \pm 0.40 \\
\quad \text { Unclear }\end{array}$ & $\begin{array}{c}0.76 ; \times / \div 1.26 \\
-0.47 ; \pm 0.39 \\
\text { Small } \downarrow\end{array}$ & $\begin{array}{l}0.85 ; \times / \div 1.21 \\
-0.28 ; \pm 0.32, \\
\text { Small } \downarrow\end{array}$ \\
\hline Creatine kinase & $\begin{array}{l}1.90 \times / \div 1.20 \\
0.83 ; \pm 0.23 \\
\quad \text { Moderate } \uparrow\end{array}$ & $\begin{array}{c}1.97 \times / \div 1.30 \\
0.88 ; \pm 0.35 \\
\text { Moderate } \uparrow\end{array}$ & $\begin{array}{l}2.28 \times 1 \div 1.24 \\
1.07 ; \pm 0.28 \\
\quad \text { Moderate } \uparrow\end{array}$ & $\begin{array}{l}0.87 ; \times / \div 1.37 \\
-0.19 ; \pm 0.41 \\
\quad \text { Unclear }\end{array}$ & $\begin{array}{l}0.83 ; \times / \div 1.29 \\
-0.24 ; \pm 0.33 \\
\quad \text { Small } \downarrow\end{array}$ & $\begin{array}{l}0.96 ; \times / \div 1.35 \\
-0.05 ; \pm 0.39 \\
\text { Unclear }\end{array}$ \\
\hline Myoglobin & $\begin{array}{l}0.97 \times / \div 1.13 \\
-0.10 ; \pm 0.38 \\
\quad \text { Unclear }\end{array}$ & $\begin{array}{l}1.17 \times / \div 1.15 \\
0.48 ; \pm 0.42 \\
\quad \text { Small } \uparrow\end{array}$ & $\begin{array}{l}1.26 \times 1 \div 1.17 \\
0.70 ; \pm 0.48 \\
\quad \text { Moderate } \uparrow\end{array}$ & $\begin{array}{l}0.93 ; \times / \div 1.21 \\
-0.22 ; \pm 0.58 \\
\quad \text { Small } \downarrow\end{array}$ & $\begin{array}{l}0.77 ; \times / \div 1.20 \\
-0.80 ; \pm 0.55 \\
\quad \text { Moderate } \downarrow\end{array}$ & $\begin{array}{l}0.83 ; \times / \div 1.18 \\
-0.58 ; \pm 0.51, \\
\text { Small } \downarrow\end{array}$ \\
\hline Interleukin-6 & $\begin{array}{c}1.02 \times 1 \div 1.30 \\
0.02 ; \pm 0.24 \\
\quad \text { Unclear }\end{array}$ & $\begin{array}{c}1.23 \times / \div 1.60 \\
0.19 ; \pm 0.42 \\
\text { Unclear }\end{array}$ & $\begin{array}{c}1.03 \times 1 \div 1.39 \\
0.02 ; \pm 0.30 \\
\text { Unclear }\end{array}$ & $\begin{array}{c}1.20 ; \times / \div 1.70 \\
0.17 ; \pm 0.48 \\
\quad \text { Unclear }\end{array}$ & $\begin{array}{c}0.99 ; \times / \div 1.46 \\
-0.01 ; \pm 0.34 \\
\text { Unclear }\end{array}$ & $\begin{array}{c}0.83 ; \times / \div 1.66 \\
-0.17 ; \pm 0.46 \\
\text { Unclear }\end{array}$ \\
\hline Interleukin-10 & $\begin{array}{c}0.87 \times / \div 1.32 \\
-0.24 ; \pm 0.46 \\
\text { Unclear }\end{array}$ & $\begin{array}{c}0.91 \times 1 \div 2.49 \\
-0.15 ; \pm 1.54 \\
\text { Unclear }\end{array}$ & $\begin{array}{l}0.88 \times / \div 1.18 \\
-0.21 ; \pm 0.28 \\
\quad \text { Small } \downarrow\end{array}$ & $\begin{array}{c}1.03 ; \times 1 \div 2.50 \\
0.05 ; \pm 1.55 \\
\quad \text { Unclear }\end{array}$ & $\begin{array}{c}0.98 ; \times 1 \div 1.34 \\
-0.03 ; \pm 0.49 \\
\text { Unclear }\end{array}$ & $\begin{array}{c}0.95 ; \times 1 \div 2.52 \\
-0.08 ; \pm 1.57 \\
\text { Unclear }\end{array}$ \\
\hline
\end{tabular}

Note: The magnitude of difference between treatments was assessed using the following criteria: trivial $<0.2$, small $0.2-0.6$, moderate $0.6-1.2$, large $1.2-2.0$, and very large $>2.0$. CWI $=$ cold water immersion, COMP $=$ compression garments, CON $=$ control (carbohydrate + stretching). $\uparrow=$ increase in concentration; $\downarrow=$ decrease in concentration. 
a

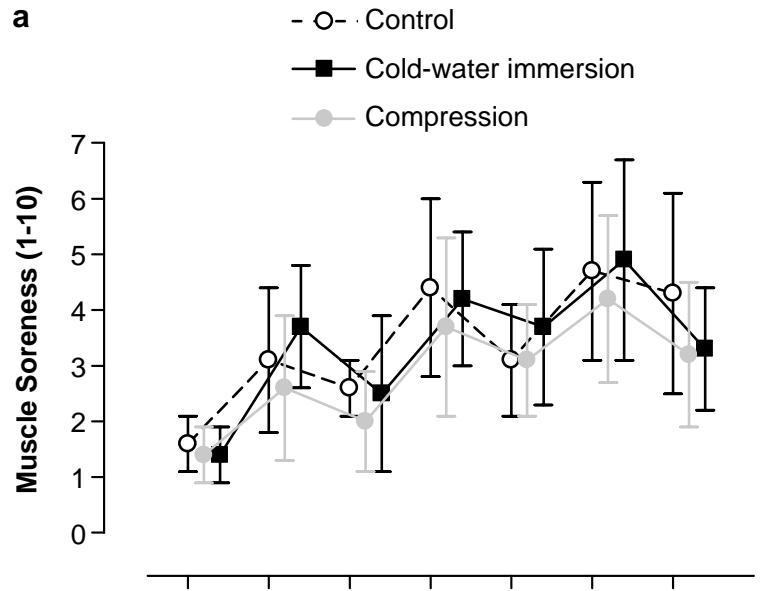

b

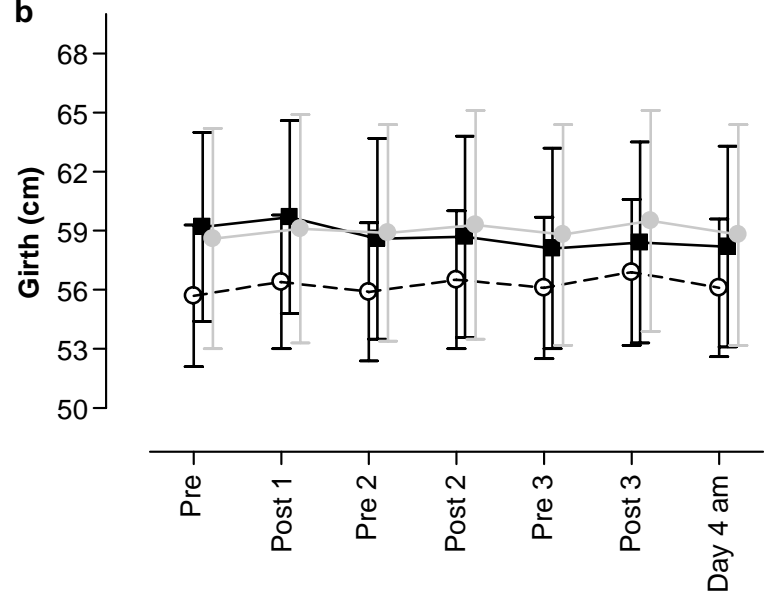

Figure 4. Muscle soreness (a) and thigh girth (b) during a threegame basketball tournament. Values are means and standard deviations. Pre values are measures taken on the morning before each game; Post values are the measures taken immediately after each game. Soreness increased for all treatments over the tournament period. Cold water immersion had a very large benefit in reducing muscle soreness compared with compression and a control treatment on the morning of the fourth day. Thigh girth increased slightly over the tournament period in the compression and control treatments, with a trivial decrease after cold water immersion.

soreness post-game, with no treatment having a clear benefit. On the morning following treatment, soreness decreased for all groups, with cold water immersion and compression having unclear small and trivial benefits respectively compared with the control treatment.

\section{Thigh girth}

The pre- to post-game and the morning after recovery intervention changes in mid-thigh girth are shown in Table II. Neither cold water immersion nor compression was more beneficial than the control treatment, with trivial changes in thigh girth between treatments after games or the tournament (Figure 4b).

\section{Discussion}

The plasma concentration of several muscle damage markers and inflammatory cytokines increased substantially (up to about four-fold) during tournament-style basketball competition, before returning to baseline values within $24 \mathrm{~h}$. The application of immediate cold water immersion or compression had little benefit in decreasing biomarker concentrations measured $6 \mathrm{~h}$ after a game. However, using immediate cold water immersion had a small to moderate benefit in enhancing biomarker clearance compared with compression and traditional carbohydrate + stretching routines between games during the competition period. After 3 days of competition, cold water immersion also had a moderate impact on decreasing biomarker concentration compared with the compression and control strategies. It appears that cold water immersion recovery is a useful intervention in a multi-day basketball tournament setting.

The magnitudes of increase $(\sim 1.5$-fold) in creatine kinase concentrations are substantially less than those in previous studies of the effects of eccentricbased exercise, probably due to the extreme nature of previous protocols. However, these changes are consistent with the effects of concentric exercise (Bailey et al., 2007). Creatine kinase concentration may decrease slightly $10 \mathrm{~h}$ after concentric exercise, without returning to baseline values within $24 \mathrm{~h}$ (Clarkson, Byrnes, McCormick, Turcotte, \& White, 1986). This pattern of response may indicate that both eccentric and concentric exercise is responsible for mild membrane damage or increased permeability after a game. The time courses of changes in FABP and myoglobin kinetics post-game were parallel to each other, with substantial reductions $6 \mathrm{~h}$ after play. The acute elevation and rapid clearance of FABP and myoglobin compared with the sustained elevation of creatine kinase indicates that these biomarkers are more appropriate for quantifying alterations in muscle cell membrane permeability between games in tournament-style competition.

It is reasonable to assume some degree of mechanical damage occurred due to the nature of basketball play. Previous reports on distance running suggest that increased serum concentrations of creatine kinase and myoglobin may be a result of free radical-induced membrane permeability, and not mechanical muscle damage (Goodman et al., 1997). Increased free radical production during exercise may augment membrane permeability, allowing protein efflux into the circulation for detection post-exercise. Although we did not measure free radical concentrations, a limited free radical and metabolic response, causing a modest decrease in membrane integrity, might explain our observations 
Table II. Pre- to post-tournament responses to muscle soreness (1-10 visual analogue scale) and thigh girth measures (mm) (values are shown as raw means $\pm \mathrm{s}$, with the associated effect size and qualitative outcome shown in italics)

\begin{tabular}{|c|c|c|c|c|c|c|}
\hline & \multicolumn{3}{|c|}{$\begin{array}{c}\text { Changes } \\
\text { (raw means } \pm s \text { ) } \\
\text { Effect size; } \pm C L, \\
\text { Qualitative outcome }\end{array}$} & \multicolumn{3}{|c|}{$\begin{array}{c}\text { Effects } \\
\text { (mean; } \pm 90 \% \text { confidence limits) } \\
\text { Effect size; } \pm C L, \\
\text { Qualitative outcome }\end{array}$} \\
\hline & CWI & COMP & $\mathrm{CON}$ & $\mathrm{COMP} / \mathrm{CON}$ & $\mathrm{CWI} / \mathrm{CON}$ & CWI/COMP \\
\hline \multicolumn{7}{|l|}{ Changes over tournament } \\
\hline Muscle soreness $(1-10)$ & $\begin{array}{r}1.3 \pm 0.7 \\
2.60 ; \pm 1.32 \\
\text { Very large } \uparrow\end{array}$ & $\begin{array}{l}1.9 \pm 0.8 \\
3.89 ; \pm 1.55 \\
\quad \text { Very large } \uparrow\end{array}$ & $\begin{array}{l}2.9 \pm 1.4 \\
5.80 ; \pm 2.84, \\
\text { Very large } \uparrow\end{array}$ & $\begin{array}{c}-1.00 ; \pm 1.50 \\
-1.91 ; \pm 3.05 \\
\text { Unclear }\end{array}$ & $\begin{array}{l}-1.60 ; \pm 1.50 \\
-3.21 ; \pm 2.96, \\
\quad \text { Very large } \downarrow\end{array}$ & $\begin{array}{c}-0.60 ; \pm 0.90 \\
-1.30 ; \pm 1.87, \\
\text { Large } \downarrow\end{array}$ \\
\hline Thigh girth (mm) & $\begin{array}{c}-0.07 \pm 0.66 \\
-0.01 ; \pm 0.13 \\
\text { Trivial? }\end{array}$ & $\begin{array}{l}0.54 \pm 0.21 \\
0.11 ; \pm 0.04 \\
\text { Trivial } \uparrow\end{array}$ & $\begin{array}{l}0.68 \pm 0.28 \\
0.14 ; \pm 0.06 \\
\text { Trivial } \uparrow\end{array}$ & $\begin{array}{c}-0.14 ; \pm 0.32 \\
-0.03 ; \pm 0.06 \\
\text { Trivial ? }\end{array}$ & $\begin{array}{c}-0.75 ; \pm 0.68 \\
-0.15 ; \pm 0.14 \\
\text { Trivial } \downarrow\end{array}$ & $\begin{array}{c}-0.61 ; \pm 0.67 \\
-0.12 ; \pm 0.13 \text {, } \\
\text { Trivial } \downarrow\end{array}$ \\
\hline
\end{tabular}

Note: Outcomes were assessed by using the following criteria: trivial $<0.2$, small $0.2-0.6$, moderate $0.6-1.2$, large $1.2-2.0$, and very large $>$ 2.0. $\mathrm{CWI}=$ cold water immersion, $\mathrm{COMP}=$ compression garments, $\mathrm{CON}=$ control (carbohydrate + stretching). $\uparrow=$ increase in concentration; $\downarrow=$ decrease in concentration.

of relatively modest elevations in these biomarkers. Restoration of membrane integrity or biomarker normalization is not influenced by differing recovery treatments, particularly within the first $6 \mathrm{~h}$. However, within $24 \mathrm{~h}$ and after the tournament we observed lower FABP and myoglobin concentrations, and a decrease in the rate of elevation of creatine kinase, for cold water immersion compared with the other two treatments. Although a previous study indicated that a single bout of cold water immersion had no benefit (Sellwood et al., 2007), our findings indicate (indirectly) that repeated daily cold water immersion has a positive effect on restoring or maintaining membrane integrity during tournament-style competition. One possible explanation may be the compounding effect of repeated daily exposure enhancing fluid gradients and fluid shifts due to the increased hydrostatic pressure encountered during immersion (Stocks et al., 2004; Wilcock, Cronin, \& Hing, 2006).

Both IL-6 and IL-10 concentrations increased sharply after each game, but it is unclear whether these elevations were related solely to an inflammatory response. The IL- 6 kinetics observed immediately after basketball games are consistent with previous reports (Pedersen, 2000; Suzuki et al., 2000), coinciding with the greatest neutrophil activity after exercise. However, as the post-exercise increases in IL-6 are dose-dependent (Pedersen, 2000), the approximately three- to four-fold increase observed after a game of basketball is much lower than previously reported, and is presumably influenced by other factors. Interleukin- 6 has a regulatory role in carbohydrate availability, and the serum concentration of IL- 6 can be attenuated by carbohydrate ingestion during running-based exercise (Starkie et al., 2001). We restricted athletes from ingesting fluids containing carbohydrate during play, but held intake constant between games. The acute postgame increase may be due to up-regulated signalling pathways associated with increased carbohydrate availability during play. Additionally, IL-6 may increase due to a progressive increase in core temperature (Rhind et al., 2004), which presumably occurred during the games. The observed changes in IL-10 concentration provide indirect evidence of an activated inflammatory cascade directly after a game. However, it is unclear whether IL-10 is produced in reaction to a localized production of IL- 6 within a generalized inflammatory response (Peake, Nosaka, \& Suzuki, 2005), or to an elevated IL-6 concentration associated with other metabolic factors that may, or may not, be related to muscle damage.

The benefits associated with cold water immersion observed in the current study may be related to a redistribution of oedema from enhanced fluid gradients, shunting of increased peripheral blood to the central blood volume related to hydrostatic pressure (Stocks et al., 2004; Wilcock et al., 2006), or pain inhibition. The combination of cold water and hydrostatic pressure may have enhanced lymph flow, decreasing oedema. Lymph evacuation is influenced significantly when cold water is applied with or without pressure (Meeusen et al., 1998). In contrast, the level of compression created by commercial garments was not sufficient to elicit a substantial impact. The biphasic response in muscle soreness coincides with the acute changes in biomarkers following games. The lowering of muscle temperature may be one explanation for the greater decrease in pain perception immediately after and the morning after cold water immersion. Lowering tissue temperature by $10-15^{\circ} \mathrm{C}$ inhibits the painspasm cycle by reducing nerve conduction velocity, muscle spindle activity, muscle spasticity, and the 
stretch-reflex response (Meeusen \& Lievens, 1986). The compounding effect of repeated daily exposure may account for the substantial benefit observed with cold water immersion compared with the other two treatments.

There was large variation in the individual postgame responses between players. The immediate explanation of this may be the between-participant differences in workloads. However, our analysis accounted for cumulative game time as a covariate, essentially normalizing game time across all players. Therefore, the variation in results indicates that certain players may be more or less susceptible to alterations in myocyte membrane permeability, or have differing biomarker clearance rates. Regardless of the mechanism, the findings suggest a need for individualized recovery programmes. Further research is required to develop a practical method for identifying and managing players requiring more extensive or intensive recovery after training and competitive games.

\section{Conclusions}

Tournament-style basketball play elicits modest elevations in muscle damage markers in the circulation, suggesting disruption of myocyte membrane permeability in well-trained players. The magnitude of increase in muscle damage markers and inflammatory cytokines post-game ranged from small for creatine kinase to very large for fatty-acid binding protein and myoglobin. Small to moderate decreases in biomarker concentration were evident after the tournament using cold water immersion compared with compression and a carbohydrate + stretching routine. The application of compression garments appears to have little advantage in enhancing clearance over consecutive days, but a study with a larger sample size is needed to resolve this issue. Repeated competition initiates acute localized membrane permeability and restoration, with an associated inflammatory cytokine response. However, it is unclear whether this is a true inflammatory response associated with mechanical damage or other metabolic mechanisms. Cold water immersion provides an acute analgesic effect and appears most effective in enhancing recovery after repeated application. Players should undertake this form of recovery as part of the regular post-game management. Further research is required to determine the effectiveness of other water-based treatments, such as contrast hot and cold water immersion, and the physiological mechanisms underpinning improved recovery in the team-sport setting.

\section{References}

Abdelkrim, N. B., El Fazaa, S., \& El Ati, J. (2007). Time-motion analysis and physiological data of elite under-19-year-old basketball players during competition. British fournal of Sports Medicine, 41, 69-75; discussion 75.

Bailey, D. M., Erith, S. J., Griffin, P. J., Dowson, A., Brewer, D. S., Gant, N., et al. (2007). Influence of cold-water immersion on indices of muscle damage following prolonged intermittent shuttle running. Fournal of Sports Sciences, 25, 1163-1170.

Burke, L. M. (2001). Energy needs of athletes. Canadian fournal of Applied Physiology, 26(suppl.), S202-S219.

Clarkson, P. M., Byrnes, W. C., McCormick, K. M., Turcotte, L. P., \& White, J. S. (1986). Muscle soreness and serum creatine kinase activity following isometric, eccentric, and concentric exercise. International Fournal of Sports Medicine, 7, 152-155.

Duffield, R., \& Portus, M. (2007). Comparison of three types of full-body compression garments on throwing and repeat-sprint performance in cricket players. British fournal of Sports Medicine, 41, 409-414; discussion 414.

Febbraio, M. A., \& Pedersen, B. K. (2002). Muscle-derived interleukin-6: Mechanisms for activation and possible biological roles. FASEB fournal, 16, 1335-1347.

Gill, N. D., Beaven, C. M., \& Cook, C. (2006). Effectiveness of post-match recovery strategies in rugby players. British fournal of Sports Medicine, 40, 260-263.

Goodman, C., Henry, G., Dawson, B., Gillam, I., Beilby, J., Ching, S., et al. (1997). Biochemical and ultrastructural indices of muscle damage after a twenty-one kilometre run. Australian Fournal of Science and Medicine in Sport, 29, 95-98.

Hopkins, W. G. (2006). Spreadsheets for analysis of controlled trials, with adjustment for a subject characteristic. Sportscience, $10,46-50$.

Janeira, M. A., \& Maia, J. (1998). Game intensity in basketball: An interactionist view linking time-motion analysis, lactate concentration and heart rate. Coaching and Sport Science fournal, 3, 26-30.

Mair, J., Mayr, M., Muller, E., Koller, A., Haid, C., ArtnerDworzak, E., et al. (1995). Rapid adaptation to eccentric exercise-induced muscle damage. International fournal of Sports Medicine, 16, 352-356.

McInnes, S. E., Carlson, J. S., Jones, C. J., \& McKenna, M. J. (1995). The physiological load imposed on basketball players during competition. Fournal of Sports Sciences, 13, 387-397.

Meeusen, R., \& Lievens, P. (1986). The use of cryotherapy in sports injuries. Sports Medicine, 3, 398-414.

Meeusen, R., van der Veen, P., Joos, E., Roeykens, J., Bossuyt, A., \& De Meirleir, K. (1998). The influence of cold and compression on lymph flow at the ankle. Clinical fournal of Sports Medicine, 8, 266-271.

Nosaka, K., Sakamoto, K., Newton, M., \& Sacco, P. (2001). How long does the protective effect on eccentric exercise-induced muscle damage last? Medicine and Science in Sports and Exercise, 33, 1490-1495.

Paddon-Jones, D., \& Abernethy, P. J. (2001). Acute adaptation to low volume eccentric exercise. Medicine and Science in Sports and Exercise, 33, 1213-1219.

Peake, J., Nosaka, K., \& Suzuki, K. (2005). Characterization of inflammatory responses to eccentric exercise in humans. Exercise Immunology Review, 11, 64-85.

Pedersen, B. K. (2000). Special feature for the Olympics. Effects of exercise on the immune system: Exercise and cytokines. Immunology and Cell Biology, 78, 532-535.

Pedersen, B. K., \& Febbraio, M. (2005). Muscle-derived interleukin-6 - a possible link between skeletal muscle, adipose tissue, liver, and brain. Brain, Behavior and Immunity, 19, 371376. 
Pedersen, B. K., Steensberg, A., Keller, P., Keller, C., Fischer, C., Hiscock, N., et al. (2003). Muscle-derived interleukin-6: Lipolytic, anti-inflammatory and immune regulatory effects. Pflugers Archive, 446, 9-16.

Peterson, A. M., \& Pedersen, B. K. (2005). The anti-inflammatory effect of exercise. Fournal of Applied Physiology, 98, 1154 1162.

Rhind, S. G., Gannon, G. A., Shephard, R. J., Buguet, A., Shek, P. N., \& Radomski, M. W. (2004). Cytokine induction during exertional hyperthermia is abolished by core temperature clamping: Neuroendocrine regulatory mechanisms. International fournal of Hyperthermia, 20, 503-516.

Sellwood, K., Brukner, P., Williams, D., Nicol, A., \& Hinman, R. (2007). Ice-water immersion and delayed-onset muscle soreness: A randomised controlled trial. British fournal of Sports Medicine, 41, 392-397.

Shephard, R. J. (2002). Cytokine responses to physical activity, with particular reference to IL-6: Sources, actions, and clinical implications. Critical Reviews in Immunology, 22, 165-182.

Sorichter, S., Mair, J., Koller, A., Pelsers, M. M., Puschendorf, B., \& Glatz, J. F. (1998). Early assessment of exercise induced skeletal muscle injury using plasma fatty acid binding protein. British Fournal of Sports Medicine, 32, 121-124.

Sorichter, S., Puschendorf, B., \& Mair, J. (1999). Skeletal muscle injury induced by eccentric muscle action: Muscle proteins as markers of muscle fiber injury. Exercise Immunology Review, 5, 5-21.

Starkie, R. L., Arkinstall, M. J., Koukoulas, I., Hawley, J. A., \& Febbraio, M. A. (2001). Carbohydrate ingestion attenuates the increase in plasma interleukin-6, but not skeletal muscle interleukin-6 mRNA, during exercise in humans. Fournal of Physiology, 533, 585-591.

Stocks, J. M., Patterson, M. J., Hyde, D. E., Jenkins, A. B., Mittleman, K. D., \& Taylor, N. A. (2004). Effects of immersion water temperature on whole-body fluid distribution in humans. Acta Physiologica Scandanavica, 182, 3-10.

Suzuki, K., Yamada, M., Kurakake, S., Okamura, N., Yamaya, K., Liu, Q., et al. (2000). Circulating cytokines and hormones with immunosuppressive but neutrophil-priming potentials rise after endurance exercise in humans. European fournal of Applied Physiology, 81, 281-287.

Vaile, J. M., Gill, N. D., \& Blazevich, A. J. (2007). The effect of contrast water therapy on symptoms of delayed onset muscle soreness. Fournal of Strength and Conditioning Research, 21, 697702 .

Vincent, H., \& Vincent, K. (1997). The effect of training status on the serum creatine kinase response, soreness and muscle function following resistance exercise. International fournal of Sports Medicine, 18, 431.

Wilcock, I. M., Cronin, J. B., \& Hing, W. A. (2006). Physiological response to water immersion: A method for sport recovery? Sports Medicine, 36, 747-765.

Wodzig, K. W. H., Pelsers, M. M. A. L., Van der Vusse, G. J., Roos, W., \& Glatz, J. F. C. (1997). One-step enzyme-linked immunosorbent assay (ELISA) for plasma fatty acid-binding protein. Annals of Clinical Biochemistry, 34, 263-8. 